\title{
Analysing the applicability of deployable scissor structures in responsive building skins
}

\author{
A. Vergauwen \& N. De Temmerman \\ Department of Architectural Engineering, \\ Vrije Universiteit Brussel (VUB), Brussels, Belgium
}

\begin{abstract}
Recently, responsive building skins have gained importance in the world of architectural engineering. A lot of research has been done on control systems required to obtain responsive façades, but the real challenge today is the development of a new generation of components and structures which are able to give the building envelope the required transformability. The scope of this paper is to analyse to what extent deployable scissor structures are appropriate for use in a responsive building skin. The parameters analysed in this research are the type of transformation, the type of deployment and the morphology. Of course, a lot of other aspects have an influence on the applicability of scissors structures in the building envelope, but these fall out of the scope of this paper. The result of the analysis is a first impression on the behaviour of scissor structures in the building envelope and possible applications, based on their shape and transformation characteristics. This paper can be considered as a starting point for further development of deployable scissor structures for responsive building skins.

Keywords: responsive building skin, adaptive building skin, responsive architecture, deployable structures, pantograph structures, transformable structures, scissor structures, shape possibilities, applicability, state-of-the-art.
\end{abstract}

\section{Introduction}

With mounting concerns over global climate change and resource depletion, the need for more sustainable and energy-efficient buildings has never been higher. The building envelope, which acts as a transition between inside and outside, has become a key factor in this matter. As a result, the building envelope is more and 
more evolving towards a dynamic structure, able to modify its form in response to changes in the environment, i.e. a responsive building skin (Guzowski [1]). The actual application of responsive building skins requires the combination of two sorts of technologies: control systems, necessary to decide what to do with the information obtained and structural components and/or systems, required to change the characteristics of the façade [2]. A lot of research has been done to improve the control systems for buildings, whereas the physical design of the structural components has remained largely unchanged for many decades. To improve the performance and the practical application of responsive building skins in the future, the crucial next step is the development of a new generation of dynamic structural systems.

\section{Responsive building skins}

One of the first buildings having a responsive building skin is Jean Nouvel's l'Institut du Monde Arabe in Paris [3]. The project dates from 1989 and comprises a kinetic curtain wall that responds to the position of the sun. The system incorporates 30.000 light-sensitive diaphragms designed to regulate the penetration of light into the building (fig. 1.1). They form a geometric pattern of squares, circles and octagonal shapes, which changes during the different phases of the lens. Accordingly, the transformability of the façade is obtained by a mechanical system of overlapping stainless steel elements that open or close to permit more or less light to pass through. Unfortunately, because of mechanical failings the responsive system is no longer operational. Today, 20 years on, technological innovations and recent advances in diverse computational tools give rise to a variety of new solutions for the materialization of the adaptability in the façade. The following paragraphs give an overview of the state-of-the art of responsive building skins.

\subsection{State-of-the art of responsive building skins}

\subsubsection{Smart materials}

Smart materials are one way to change the characteristics of the façade in order to respond to changing conditions. These are objects that sense environmental events, process that sensory information and then act on the environment. Different kinds of effects can be obtained, such as a colour change, a volume change, a change of the distribution of stresses and strains or a change of index of refraction, as described by Sadeghi et al. [4]. Electronically tintable glass (or electrochromic (EC) glass) is a good example of a smart material applied in responsive building skins today.

\subsubsection{Traditional components}

The Product Innovation Award winner for 2011 selected by 'Architectural Products" is "C/S Solarmotion ${ }^{\circledR}$ Architectural Blinds". This is a high-tech system of intelligent architectural blinds which uses an intuitive control system that reacts, moves and adapts to the angle of the sun as well as to changing weather conditions, maximizing the energy efficiency of the building. In this way the 
Solarmotion system significantly reduces a building's energy and capital equipment costs [5]. Another project where traditional building components are used to obtain a responsive building skin is the Olympic Tennis Center of Madrid, designed by Dominique Perrault (fig. 1.2). The roofs of the three indooroutdoor courts are giant mobile slabs mounted on hydraulic slabs, allowing 27 different opening positions. The roofs can be vertically opened to allow for passage of air and sunlight and horizontally they slide as much as their width to make the courts completely open to the sky. In bad weather conditions, the slabs can be completely closed [6].

\subsubsection{Based on the diaphragm principle}

Chuck Hoberman [7] is founder and president of Hoberman Associates, a firm specialised in the development of retractable façades, responsive shading and ventilation, and operable roofs and canopies. In 2008, Hoberman Associates and Buro Happold worked together to form the Adaptive Building initiative (ABI) [8], with the purpose of researching and developing responsive facades. An example of their work is the Tesselate ${ }^{\mathrm{TM}}$ technology. Tesselate ${ }^{\mathrm{TM}}$ acts as a responsive sunscreen and is made up of multiple overlapping layers of perforated metal panels, creating kaleidoscopic patterns. The application of tessellate ${ }^{\mathrm{TM}}$ technology in a building, can lower its overall energy consumption with $6 \%$ and can reduce the cooling load by $15-20 \%$. The ABI's Tessellate ${ }^{\mathrm{TM}}$ system was installed in the Simons Center for Geometry \& Physics at the State University of New York in 2010 (fig. 1.3).

\subsubsection{Deployable structures}

Deployable structures are gradually finding their way into responsive building skin projects. A good example is the "Dynamic Façade" project or better known as the Kiefer Technic Showroom (in Bad Gleichenberg, Austria), created by architect Giselbrecht and partner ZT GmbH, completed in 2007 (fig. 1.4). The 112 metal tiles can fold in different positions by means of 56 engines, allowing occupants to adjust the light or temperature in a room. In this way, the façade changes continuously, each day and every hour, creating a dynamic sculpture [9]. Santiago Calatrava found inspiration in another type of deployable structure for his design of the Pfalzkeller Emergency Services Centre in St-Gallen, Switzerland, as shown in fig. 1.5. The centre is placed underground and is covered with an elliptical glass roof. To control daylight and temperature in the centre, Calatrava designed an unfolding wrap made out of slats. Yildiz [10] explains that this structure makes use of a transformable rigid bar structure, which consists of beams connected through a revolute joint allowing a relative rotation and consequently, a transformation of the structure. The Al Bahr Towers, the new Abu Dhabi Investment Council building, is a project characterized by its computer-controlled façade made up of more than 2,000 translucent parasol-like units that open and close as a response to the sun moving over their surface (fig. 1.6). The design of the engineering firm Arup and the architects of Aedas resulted in a reduction in the building's overall energy consumption and carbon footprint by $20 \%$. On the south side of the tower savings can reach up to $50 \%$, as described by Leech [11]. 

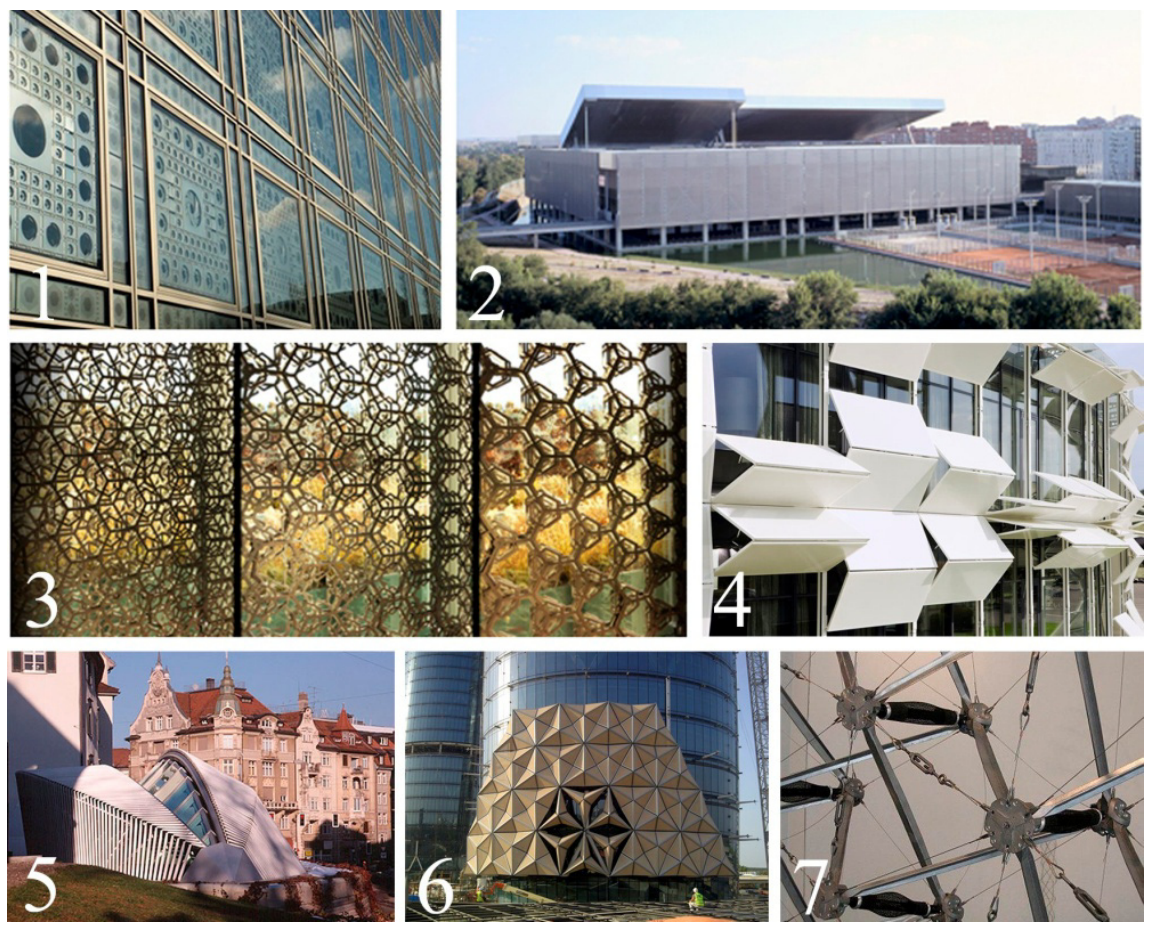

Figure 1: 1 L'Institut du Monde Arabe in Paris, designed by Jean Nouvel [3]. 2 Dominique Perrault's Olympic Tennis Centre of Madrid. 3 The ABI's Tessellate ${ }^{\mathrm{TM}}$ system in the Simons Center for Geometry \& Physics at the State University of New York, 2010. 4 The "Dynamic Façade" in Bad Gleichenberg, Austria, created by architect Giselbrecht and partner ZT GmbH (from dailytonic.com). 5 Calatrava's Pfalzkeller Emergency Services Centre in St-Gallen (photo: galinski.com). 6 The new Abu Dhabi Investment Council building, a design of Arup and Aedas (from aedasresearch.com). $7 \mathrm{~A}$ tensegrity structure for shape-changing building skins, designed by Sterk (from popsci.com).

\subsubsection{Tensegrity structures}

Another approach to obtain a responsive building skin is making the whole envelope dynamic and responsive, rather than just certain components or layers of the building skin. Tristan d'Estree Sterk, from the Office for Robotic Architectural Media and the Bureau for Responsive Architecture, is developing shape-changing 'building envelopes' based on tensegrity structures. These are lightweight skeletal frameworks composed of rods and wires and controlled by pneumatic muscles (fig. 1.7), which change the building's shape when their configuration is adjusted [2]. 


\subsection{Determining the applicability of deployable scissor structures}

These examples show that transformability in the building envelope is obtained with very different solutions and moreover, that it can have many different purposes. Deployable structures are an important and promising group in this matter, but a profound and thorough research on the different sorts of deployable structures and their potential for application in a responsive building skin is yet to be conducted. Therefore, this paper presents a concise analysis of deployable scissor structures to determine to what extent they are applicable in responsive building skins. Although other deployable structures, such as foldable plate structures, are promising with regard to application in a responsive building skin, they fall out of the scope of this paper.

\section{Deployable scissor structures}

A pair of straight and rigid bars connected with a pivot hinge, allowing the bars to rotate about an axis perpendicular to their common plane is called a scissor unit or a scissor-like element (SLE) (De Temmerman [12]). Through the interconnection of such SLE's, two- and three-dimensional panthographic transformable structures can be created. Since a scissor unit is a single-degree-offreedom mechanism, the transformation process of a scissor structure is controlled through the propagation of rotations from one scissor-pair to the next one and vice versa (Rosenberg [13]). This implies that a scissor structure can transform between different states by means of only one variable: the rotation of one component. The ability to transform their shape between a compact state and a fully deployed one, gives rise to various applications in architecture: movable theatre structures, expandable space structures, collapsible portable shelters, deployable domes and retractable roof structures (Rosenberg [13]).

\section{Analysing the potential of deployable scissor structures}

The building envelope, acting as a transition between inside and outside, has to fulfill several functional requirements. The façade provides views to the inside and the outside, absorbs forces from wind loads, allows natural light to penetrate the building while providing protection from the sun, provides insulation from heat, cold and noise, etc. All of these functional requirements are distributed among several different components in the building envelope (Knaack et al. [14]).

A responsive building skin contains components which have the ability to transform themselves in order to respond to changing parameters in their environment. The dynamic components used to obtain a responsive building skin can be very different, as demonstrated in section 2 . In order to determine to what extent deployable scissor structures are appropriate as dynamic components in a responsive building skin, the following parameters will be evaluated: the transformation type, the type of deployment and the morphology of deployable scissor structures. 


\subsection{Transformation types}

In literature, two general types of transformation can be distinguished with regard to deployable scissor structures: a transformation from a stowed configuration to an open configuration (type 1), and a transformation between intermediate states (type 2). Table 1 gives an overview of the most important differences between both transformation types and an indication of the functional requirements in the façade for which they appear appropriate.

Table 1: Overview of the transformation types.

\begin{tabular}{|c|c|c|}
\hline & Type 1 & Type 2 \\
\hline \begin{tabular}{|l|} 
Degrees of freedom \\
\end{tabular} & single & multiple \\
\hline Constraints & $\begin{array}{c}\text { fixed from one side } \\
\text { both sides unfixed }\end{array}$ & both sides fixed \\
\hline Span & variable & constant \\
\hline $\begin{array}{l}\text { Optimal stifness and } \\
\text { loadbearing capacity }\end{array}$ & $\begin{array}{c}\text { always in fully deployed } \\
\text { configuration }\end{array}$ & $\begin{array}{c}\text { varies with the shape of the } \\
\text { configuration }\end{array}$ \\
\hline $\begin{array}{l}\text { Functional } \\
\text { requirements in the } \\
\text { facade to consider }\end{array}$ & $\begin{array}{c}\text { solar shading } \\
\text { glare protection } \\
\text { relation inside-outside } \\
\text { natural ventilation control }\end{array}$ & $\begin{array}{l}\text { solar shading } \\
\text { glare protection } \\
\text { wind protection } \\
\text { noise protection }\end{array}$ \\
\hline
\end{tabular}

Due to the difference in degrees of freedom, a transformation of type 1 can (theoretically) be generated by means of only one actuation, whereas a transformation of type 2 is controlled by several actuators. The higher number of actuators needed for type 2 augments the overall complexity of the system and the energy required for the actuation, but allows for a more precise control of the structure. As a result, type 2 scissor structures appear appropriate for functional requirements which demand for a very precise control of the structure, such as noise protection, wind protection and solar shading and glare protection (when an accurate response towards the position of the sun is required).

Because both sides of a type 2 scissor structure are fixed, the span remains constant and the structure can be permanently anchored at its bearing points. As a result, the optimal stiffness and loadbearing capacity varies as the system transforms in between different intermediate states. A type 1 scissor structure on the other hand, acts as a mechanism during transformation and it is only in the fully deployed state, when the structure is fixed, that it becomes a structure with optimal stiffness and loadbearing capacity. This could turn out to be problematic when the building is subjected to great wind forces. Further research on this matter should clarify to what extent this is a setback. Nevertheless, scissor structures of type 1 appear to be appropriate for functional requirements which demand a transformation in between two states (open-closed), such as the control of natural ventilation, the control of the relation between inside and outside and solar shading and glare protection (based on the principle of opening and closing shutters). 


\subsection{Types of deployment}

Using deployable scissor structures in a responsive building skin can be considered, only if the characteristics of their deployment allow an accurate responsiveness towards varying parameters. The different types of deployment for both type 1 and 2 are described and analysed in this section.

\subsubsection{Types of deployment for scissor structures of type 1}

As mentioned before, deployable scissor structures of type 1 transform from a stowed configuration into a much larger open configuration. The type of deployment that comes along with this transformation can be very different and depends on the characteristics of the scissor units used in the structure. Table 2 gives an overview of four different types of scissor-pair units and the characteristics of their deployment.

Table 2: $\quad$ Overview of the different types of deployment for type 1.

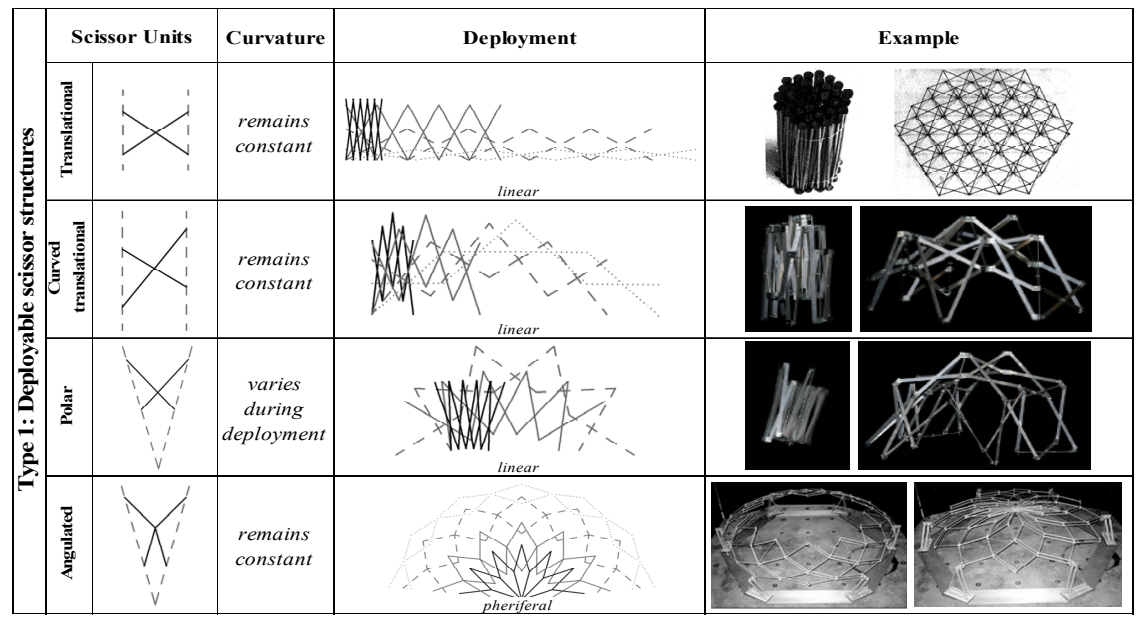

Translational units are characterized by the fact that the unit lines (the imaginary lines that connect the upper and lower end nodes of the scissor unit) are parallel and remain this way during deployment. Curved translational units are different from plane translational units because of their variable bar length (De Temmerman [12]). They are very suitable for generating arbitrary curves. Due to the eccentricity of the intermediate hinge, the unit lines of polar units are no longer parallel to each other, but intersect at an angle $\gamma$, which varies when the scissor unit deploys (Alegria Mira [15]). As a result these scissor units are typically used to generate circular arches.

Table 2 points out that (curved) translational and polar units generate a linear deployment. Since dynamic solar shading devices most often behave in a linear way (blinds, curtains, rolling shutter, etc.), a deployable scissor structure with this type of deployment appears appropriate for application in the building envelope as a solar shading or glare protection device (fig. 2a). The advantage of 
scissor structures, as opposed to existing devices, is their wide range of possible shapes, which enhances their applicability in free-form architecture (fig. 2b). Angulated elements, to conclude, are formed by two rigidly connected semi-bars that form a central kink of amplitude $\beta$. They are used to form closed-loop structures (De Temmerman [12]). A configuration of angulated elements generates a peripheral deployment, while the curvature remains constant. To allow the building skin to open and close in order to make a connection with the outside, this type of deployment behaviour is very suitable (fig. 2c). Opportunity lies within the application of peripheral deploying scissor structures in the building envelope aiming at controlling natural ventilation, thus virtually creating a 'breathing building'. By systematically opening and closing certain areas of the building skin, the indoor climate of the building could be regulated.

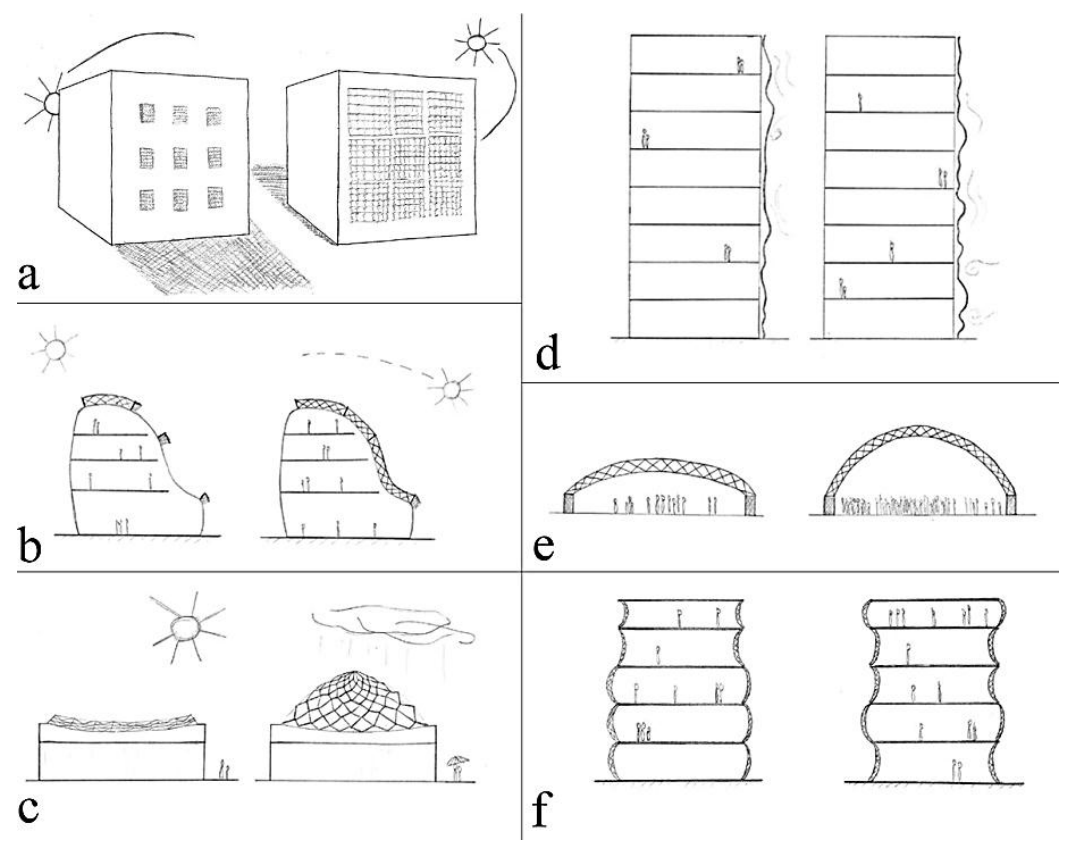

Figure 2: Conceptual illustration of applications for scissor structures in responsive building skins.

\subsubsection{Types of deployment for scissor structures of type 2}

Basically, the deployment behavior of scissor structures with intermediate states depends on the additional degrees-of-freedom added to the scissor units. Table 3 shows the different sorts of modified scissor units and their in-between states. The Cable Scissor Arch (CSA), developed by Kokawa [16], consists of three-hinged polar scissors and zigzag flexible cables through pulleys installed at the connection points between the scissor units. The structure expands and lifts up when the cable is winded by a winch. The system can only provide symmetrical arc-like shapes (Akgün [17]). In order to achieve transformations 
between curvilinear forms without changing the span length, Yenal Akgün developed the modified scissor-like element (M-SLE). The M-SLE has additional revolute joints on various locations of the bars increasing not only the degree-of-freedom of the unit, but also the transformation capacity of the whole system (Akgün [17]). Daniel Rosenberg [13] developed the double scissor pair, which offers a range of possible non-uniform shapes controlled by linear actuators. These actuators allow the scissor pair component to transform from centre to off-centre position and vice versa.

Table 3: $\quad$ Overview of the different types of deployment for type 2.

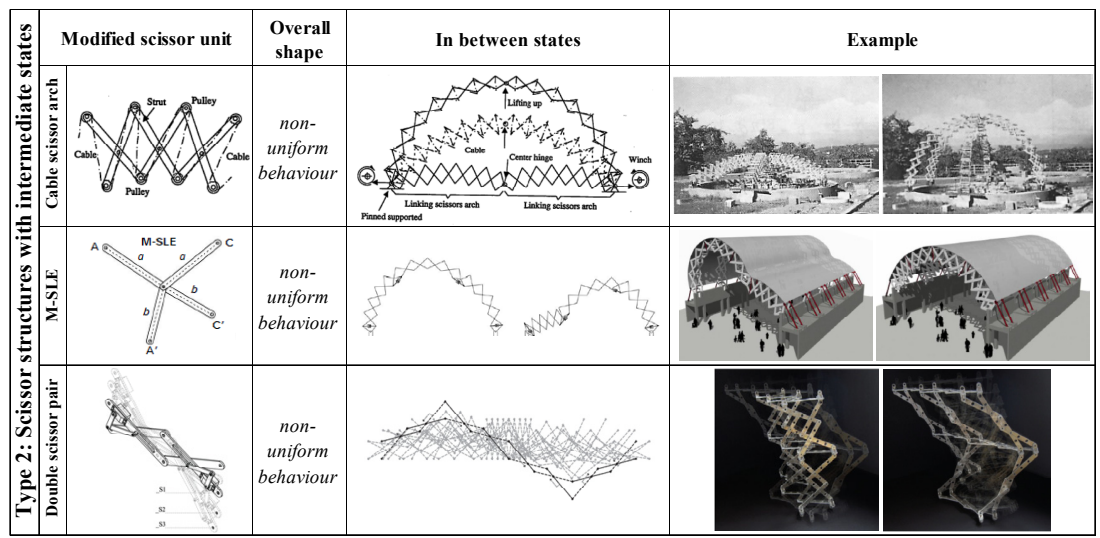

The ability of these kind of scissor structures to change in between a number of different states and consequently having a variety of different forms, makes them appropriate for functions in the building envelope which desire a maximum of flexibility. Therefore, a responsive wind or noise protection skin could be a relevant application (fig. 2d). In this case, the scissor structure adapts its form in response to the wind forces or the sound sources acting upon it. Another application, more specific for the CSA of Kokawa Tsutomu, could be a building skin which allows for volume changes in response to the amount of people, the type of activities, the season, etc. (fig 2e). The flexibility of scissor structures of type 2 could also be used for stiffness control in the building envelope (fig. 2f). It must be said that the adapted scissor units allow greater flexibility, but are therefore also more complex to control when compared to the 'classic' onedegree-of-freedom scissor units.

\subsection{Morphology}

Since the contour of the building envelope can have various forms (straight surfaces for a typical office building or curved shapes in the case of free-form architecture) the morphology of deployable scissor structures is an important parameter to evaluate.

Table 4 gives an overview of common geometrical shapes generated with linkages of scissor units. The first line of the table shows two-dimensional 
Table 4: Overview of the morphology of deployable scissor structures.

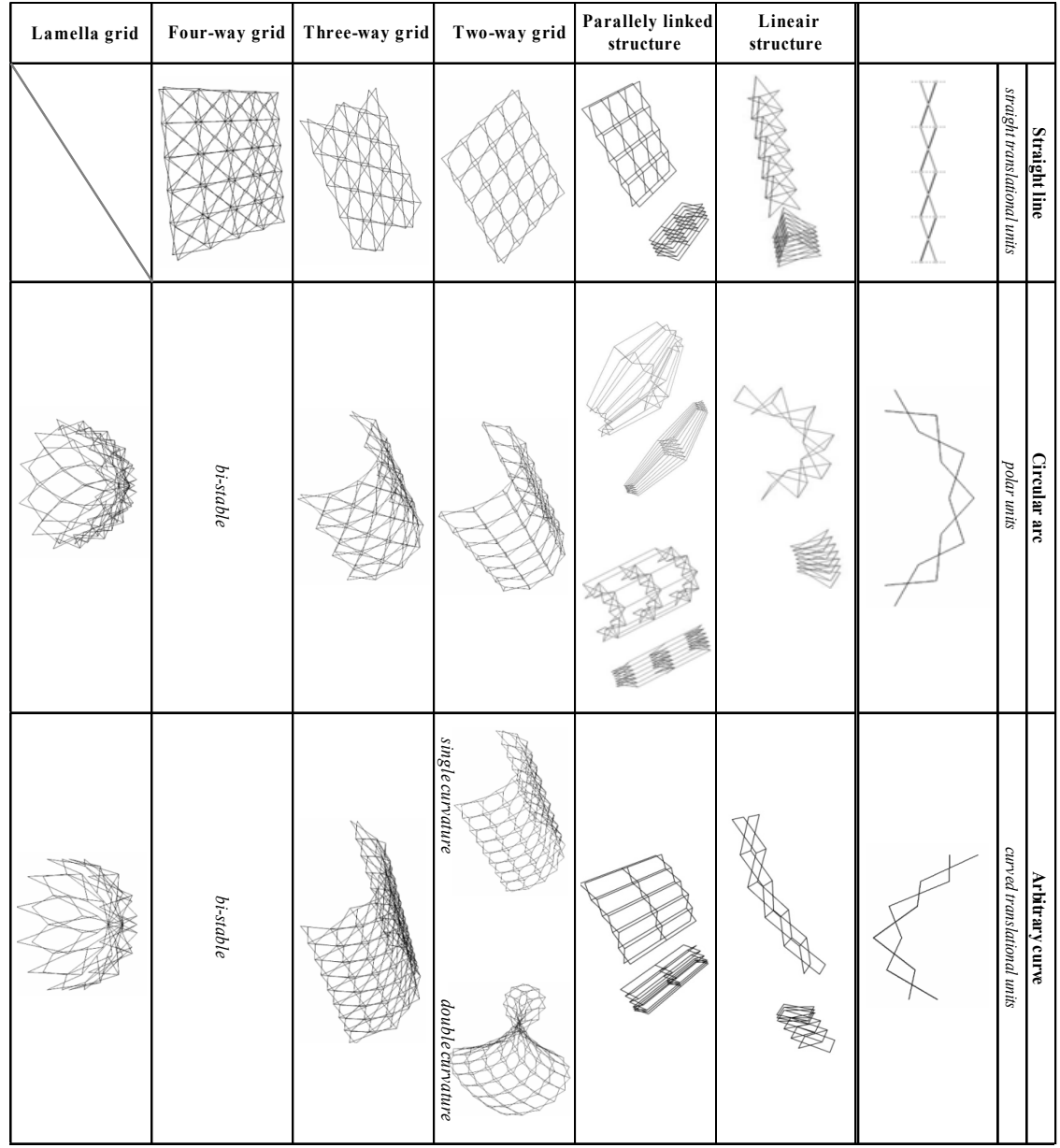

\begin{tabular}{|c|c|c|c|}
\hline Polyhedron & Hyperboloid structure & $\begin{array}{c}\text { Parallely linked } \\
\text { structure }\end{array}$ & $\begin{array}{c}\text { Lineair } \\
\text { structure }\end{array}$ \\
\hline & & \\
\hline
\end{tabular}

linkages, formed with each type of scissor unit: a straight line, a circular arc, an arbitrary curve and a closed loop. Based on these two-dimensional shapes, the table is extended with a whole collection of three-dimensional shapes. Structures consisting of (curved) translational and polar units are primarily characterized by their overall curvature (flat, single, double) and their grid direction (linear, two-, three-, or four-way). Structures based on a closed loop consisting of angulated 
elements are characterized by different parameters. The number of units in the closed loop is a first parameter, which distinguishes linear structures (small number of units in the closed loop) from hyperboloid structures (high number of units in the closed loop). A difference is also made between structures which deploy from the perimeter and structures which deploy from a center point, like the group of polyhedron structures for instance. This wide range of possible shapes has a positive impact on the applicability of deployable scissor units in responsive building skins.

\section{Conclusion}

Depending on the transformation type, deployable scissor structures appear to be more or less suitable for certain functions in the façade. The characteristics of the deployment give rise to a variety of more specific applications, such as responsive solar shading or a 'breathing building skin'. Due to the diversity regarding the morphology, deployable scissor structures show great potential for application in free-form architecture. It can be concluded that the analysis in this paper gives a first impression on the applicability of deployable scissor structures in responsive building skins and exposed some advantages and drawbacks which call for a more profound study.

Obviously, the analysis in this paper was confined to shape and transformation characteristics, while other factors need to be considered in order to thoroughly determine the applicability of scissor structures. An important factor to start with is the covering of the scissor structures. In general, flexible materials, able to follow the deployment of the scissor structure are required. But other solutions are possible, such as replacing bar elements with plate elements (Jensen [18]). Another important parameter to consider is the weight of the scissor structure. If the weight is substantially higher than the common weight of a high quality façade, the impact on the bearing structure of the building and consequently on the total cost should not be underestimated. The construction and maintenance of scissor structures as a part of the building envelope is another important aspect not to be neglected. The fact that scissor structures can deploy into a compact bundle brings along great advantages, like prefabrication and compact transport. They consist of bar elements connected by pivot hinges, which means that damaged parts can easily be removed and replaced.

The analysis in this paper is a starting point for a more profound analysis and represents the first step in the development of scissor structures for responsive building skins as an innovative type of high performance structure.

\section{References}

[1] Guzowski, M., Towards zero-energy architecture New solar design (chapter 4). Using responsive envelopes, Lawrence King Publishing, pp. 124-161, 2010.

[2] Buildings with minds of their own, The Economist newspaper, Science \& technology, http://www.economist.com/node/8312200?story_id=8312200 
[3] ArchDaily, AD Classics, Institut du Monde Arabe Jean Nouvel, http://www.archdaily.com/162101/ad-classics-institut-du-mondearabe-jean-nouvel/

[4] Sadeghi, M. J., Masudifar, P., Faizi, F., The Function of Smart Material's behavior in architecture, Proc of the 2011 International Conference on Intelligent Building and Management CSIT, IACSIT Press, Singapore, vol.5, pp. 317-322, 2011.

[5] C-sgroup website, Solar motion, http://www.c-sgroup.com/solarmotion

[6] Perrault architecte website, http://www.perraultarchitecte.com/en/ projects/2461-olympic tennis centre.html

[7] Hoberman, C. and Schwitter C., Adaptive Structures: Building for Performance and Sustainability, Design Intelligence website, 2008, http://www.di.net/articles/archive/2881/

[8] ABI website, http://www.adaptivebuildings.com/simons-center.html

[9] Kiefer Technik Showroom, http://www.worldarchitecture news.com/index.php?fuseaction=wanappln.projectview\&upload_id=18072

[10] Yildiz, A. E., Mobile structures of Santiago Calatrava: other ways of producing architecture, Master Thesis, Middle East Technical University, January 2007.

[11] Leech, N., Desert-smart towers carry their own sunscreen, The National newspaper, published on Sunday, September 25, 2011.

[12] De Temmerman, N., Design and analysis of deployable bar structures for mobile architectural applications, Vrije Universiteit Brussel, 2007.

[13] Rosenberg, D., Designing for uncertainty Novel shapes and behaviours using scissor-pair transformable structures, Universidad Catolica de Chile, 2005.

[14] Knaack, U. et al., Façades principles of construction (chapter 3). Principles of construction, Birkhauser verlag AG, pp. 36-51, 2007

[15] Alegria Mira, L., Design and analysis of u universal scissor component for mobile architectural applications, Vrije Universiteit Brussel, 2010.

[16] Kokawa, T. Cable Scissors Arch-Marionettic structure, Structural Morphology Towards the New Millennium, IASS International Colloquium, University of Nottingham, 1997/08, pp. 107-114, 1997.

[17] Akgün, Y., A novel transformation model for deployable scissor-hinge structures, Universität Stuttgart, 2010.

[18] Jensen F.V. Concepts for retractable roof structures, $\mathrm{PhD}$ dissertation, University of Cambridge, 2004. 